\title{
CARACTERIZAÇÃO DA DINÂMICA COSTEIRA DA PRAIA DE GALINHOS/RN
}

\author{
Marcelo dos Santos Chaves ${ }^{(a)}$, Zuleide Maria Carvalho Lima ${ }^{(b)}$ Iracema Miranda da Silveira $^{(\mathrm{c})}$ \\ (a) Departamento de GeografiaUniversidade Federal do Rio Grande do Norte, mschaves2007@gmail.com. \\ (b) Departamento de Geografia/Universidade Federal do Rio Grande do Norte, zuleide@ufrnet.br. \\ ${ }^{(C)}$ Museu Câmara Cascudo. Iracema_miranda@hotmail.com.
}

\section{Eixo 4: DINÂMICA E GESTÃO DE ZONAS COSTEIRAS}

\begin{abstract}
Resumo
Esta pesquisa contempla um panorama do relevo de um trecho da praia de Galinhos, litoral Setentrional do Estado do Rio Grande do Norte. Inserida numa paisagem costeira dinâmica, a área em estudo é caracterizada pela sua complexidade de suas feições geomorfológicas, representadas por praias, recifes, estuários, mangues, lagos, lagoas, dunas e esporões arenosos (spit). Esta, visa um melhor entendimento dos processos dinâmicos atuantes, afim de dar subsídios às medidas de proteção ambiental e do monitoramento costeiro. Como objetivos, destacamos o entendimento, monitoramento e caracterização da dinâmica costeira, com levantamento de dados mensais de perfis de praia e da hidrodinâmica costeira, coletados entre os meses de junho a dezembro de 2012 . Constatamos com os resultados que em todos os pontos estudados, a referida praia apresenta-se como sendo uma praia reflectiva, e que exige um monitoramento constante que indique a continuidade ou não deste comportamento praial.
\end{abstract}

Palavras-Chaves: Praia, Costeira, Monitoramento, Dinâmica

\section{1 - Introdução}

A área em estudo é o trecho da praia de Galinhos, litoral setentrional do Estado do Rio Grande do Norte (RN), Nordeste do Brasil, distante da capital Natal/RN, por via rodoviária, cerca de $174 \mathrm{~km}$ (Figura 01).

A praia é um sistema litoral onde se acumulam os sedimentos depositados pelo mar, cuja mobilidade e disposição dos mesmos ao longo da praia, depende de um conjunto de fatores como a ação e o ângulo de incidência das ondas na linha de costa, a dimensão da altura da maré, bem como o declive e a morfologia da praia. A praia pode ainda apresentar diversos perfis do tipo reflectivo (de calmaria ou de verão). Este perfil ocorre após longos períodos de tempo cuja ondulação apresenta uma fraca magnitude, levando à migração dos sedimentos contidos na praia submersa para a praia emersa ou do tipo perfil dissipativo, que geralmente ocorre em períodos de forte agitação marítima (perfil mais irregular e de forma côncava), visto que esta leva a que a areia depositada na praia emersa seja arrastada para a praia submersa, formando coroas e por fim o perfil. 


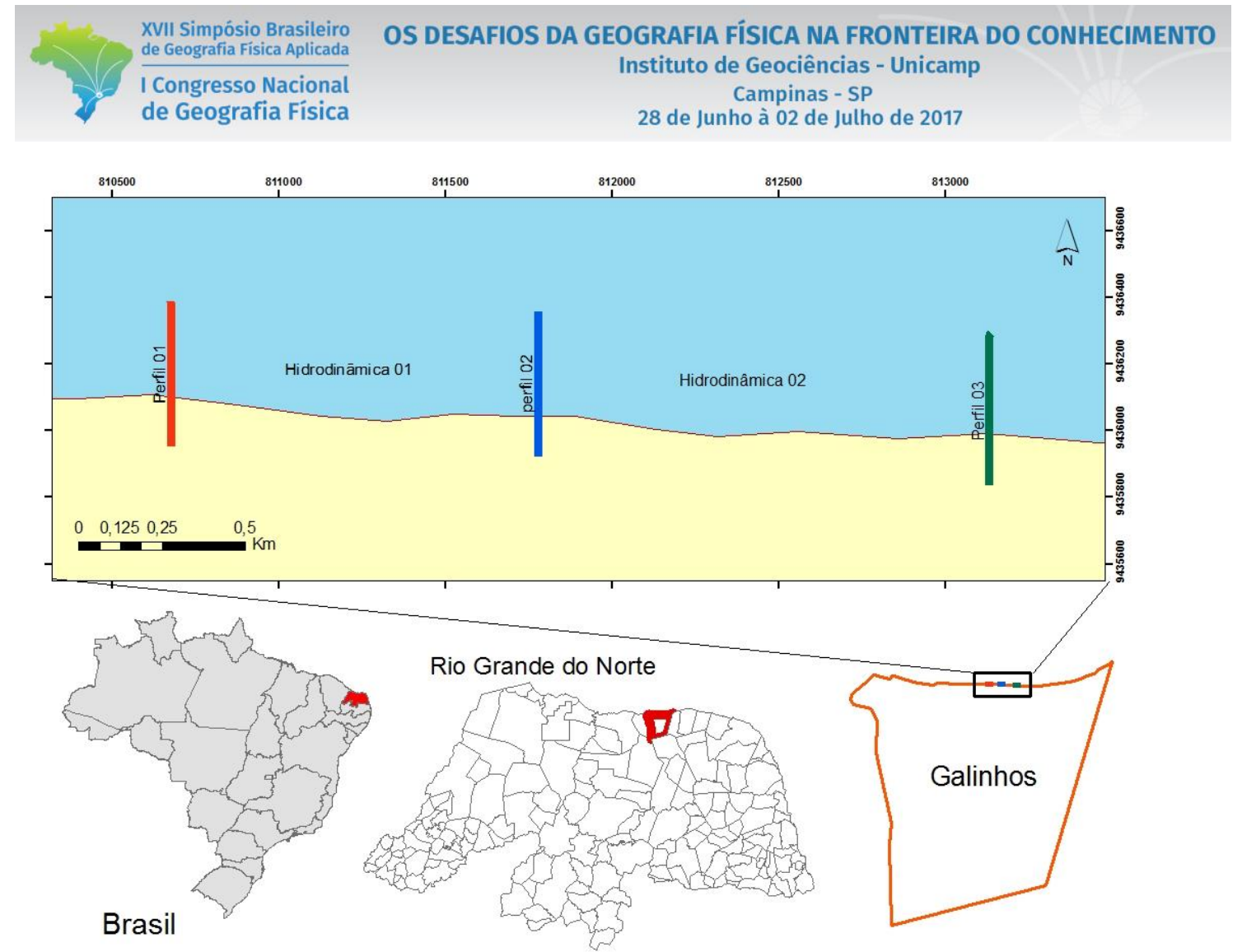

Figura 01 - Mapa de localização da área em estudo.

As ondas são o primeiro agente dos processos costeiros na linha de costa (Dean \& Dalrymple, 2002). Com isso, as elevações e contornos de uma linha de costa são respostas às forças resultantes das ondas, ventos e correntes, e dependem do suprimento sedimentar para a praia (Dean e Dalrymple, 2002, op.cit). Medindo repetidamente as dimensões de uma praia, podemos quantificar a erosão ou deposição ocorrida, bem como fornecer indicações sobre para onde o material está sendo transportado. A expressão mais simples de uma praia é o seu perfil transversal. O perfil de praia registra a altura, largura, inclinação e o volume de uma praia, enquanto perfis sequenciais registram mudanças temporais ao longo da praia (Short,1999). O perfil de praia é importante porque pode ser visto como um mecanismo natural que provoca a arrebentação e dissipa a energia das ondas (Komar, 1998). Já as características sedimentológicas dos sedimentos (principalmente sua granulometria), têm sido utilizadas na literatura para um melhor entendimento da dinâmica sazonal dos ambientes sedimentares costeiros e caracterização dos processos deposicionais (Bittencourt et al, 1987; Saaga, 1992; Lima, 2004; entre outros). Komar (1998, op. Cit.), salienta a relação entre a variação textural dos sedimentos costeiros e as mudanças na energia de ondas, taxa de transporte e diferentes fontes de sedimentos.

Inserida numa paisagem costeira dinâmica, a área costeira de Galinhos-RN é caracterizada pela complexidade de suas feições geomorfológicas, representada por praias, recifes, estuários, mangues, lagoas, laguna, dunas e esporões arenosos (spit). O modelamento dessas feições é fruto da atuação conjunta de ondas, correntes costeiras e ventos, relacionados com as variações do nível do mar ocorridas durante o período Quaternário (Lima et al. 2001). 
O potencial cênico dessa paisagem, associado com a riqueza dos recursos naturais existentes, tem incentivado uma ocupação do solo acelerada nos últimos anos. Esta pesquisa visa um melhor entendimento dos processos dinâmicos atuantes na região costeira da praia de Galinhos, a fim de dar subsídios às medidas de proteção ambiental e monitoramento costeiro.

Toda a praia de Galinhos, constitui em um ecossistema passível de modificações rápidas, tanto naturais como antrópicas. Este ecossistema encontra-se inserido na área de influência do Pólo Petrolífero de Guamaré, estando também submetida à intensa atuação da atividade salineira, carcinicultura, turismo e, mais recentemente da exploração de energia eólica, além da previsão de implantação do Pólo Gás-Sal (exploração de sal, gás natural, petróleo e calcário), e por conseguinte é prevista a implantação de um grande complexo industrial (pólo químico e petroquímico, além de uma termelétrica) (FIERN, 1998).

Desta forma, a área em estudo é importante, tanto do ponto de vista ambiental, já que abrigam ecossistemas de alta fragilidade como dunas, praias e manguezais, quanto do ponto de vista da exploração econômica. Neste, coletamos e analisamos dados dos perfis de praia (Perfil 01, 02 e 03) e da hidrodinâmica costeira (Hidrodinâmica 01 e 02), sendo todas essas informações inseridas em ambiente de praia, conforme mostrados na figura 01 .

O objetivo geral desta pesquisa foi o entendimento da dinâmica costeira atuante na região costeira de Galinhos-RN. Como objetivos específicos destacamos o monitoramento e caracterização da dinâmica costeira da área em estudo a partir de dados mensais de perfis praiais e os dados hidrodinâmicos, coletados em um período de sete (07) meses (de junho a dezembro de 2012), levando em consideração dos estádios de equilíbrio da praia.

\section{2 - Aspectos Físicos}

Segundo Nimer (1989), o clima da região de Galinhos é quente e semi-árido, caracterizado por um período seco e com época de máxima precipitação ocorrendo no verão e no outono; este clima tem influência dos sistemas de correntes de circulação perturbada de Norte e de Leste, responsáveis por instabilidades na região Nordeste.

Segundo Cestaro (1994), as precipitações nesta área ocorrem principalmente no final do verão e no outono, de março a maio. A temperatura nesta área é bastante elevada, com média anual $26,8^{\circ} \mathrm{C}$. Fevereiro é o mês mais quente e julho o mais frio, apresentando uma média mensal de $27,5^{\circ} \mathrm{C}$ e $25,0^{\circ} \mathrm{C}$, respectivamente. A média mensal da umidade relativa do ar é de $71 \%$. A insolação média anual é de 2600 horas/ano, com média de 7,22 horas/dia. Ainda segundo Cestaro (1994, op. Cit), os ventos nesta região possuem uma velocidade média anual de $6,2 \mathrm{~m} / \mathrm{s}$. São provenientes principalmente de Leste, durante os meses de agosto a abril, e de Sudeste nos meses de maio a julho. 
A vegetação nesta região são agrupadas em três ambientes distintos: ambientes de vegetação de dunas (dunas móveis e dinas fixas), ambiente de vegetação de mangue (plantas resistente à variação de salinidade e a grande amplitude de marés) e ambiente de vegetação de caatinga (arbustivo-arbórea aberta) (ECOPLAM, 1990).

A bacia hidrográfica do município de Galinhos é composta pelos rios Camurupim e Catanduba, e por lagoas. Os rios desta bacia deságuam no Oceano Atlântico em forma de estuário, caracterizando o sistema estuarino Galinhos-Guamaré, no qual, ocorre a formação de canais de maré.

Segundo SUDENE (1971), a área é caracterizada por três diferentes tipos de solos, são eles: Areias Quartzosas Marinhas; Podzólico Vermelho Amarelo Equivalente Eutrófico e Solonchak Solonético. As Areias Quartzosas Marinhas ou Neossolos (EMBRAPA, 1999), são solos arenosos, profundos, ácidos e com baixa saturação de bases. Compreendem não somente as dunas fixas como também as dunas móveis. Já os solos Podzólico Vermelho Amarelo Equivalente Eutrófico ou Luvissolos (EMBRAPA, 1999, op. cit.), são solos com horizonte B textural, não hidromórfico. E os solos Solonchak Solonético ou Gleissolos (EMBRAPA, 1999, op. cit.), tem sua formação sob condições hidromórficas. Na região costeira, os mangues constituem o tipo de vegetação relacionada com solos dessa natureza (Oliveira et al., 1992).

A área em estudo situa-se no contexto geológico da Bacia Potiguar, extremo Nordeste do Brasil, englobando parte dos estados do Rio Grande do Norte e Ceará, estando implantada na Província Borborema, descrita por Almeida et al. (1977).

Os depósitos aflorantes na área e as feições geomorfológicas estão representados na Figura 02.

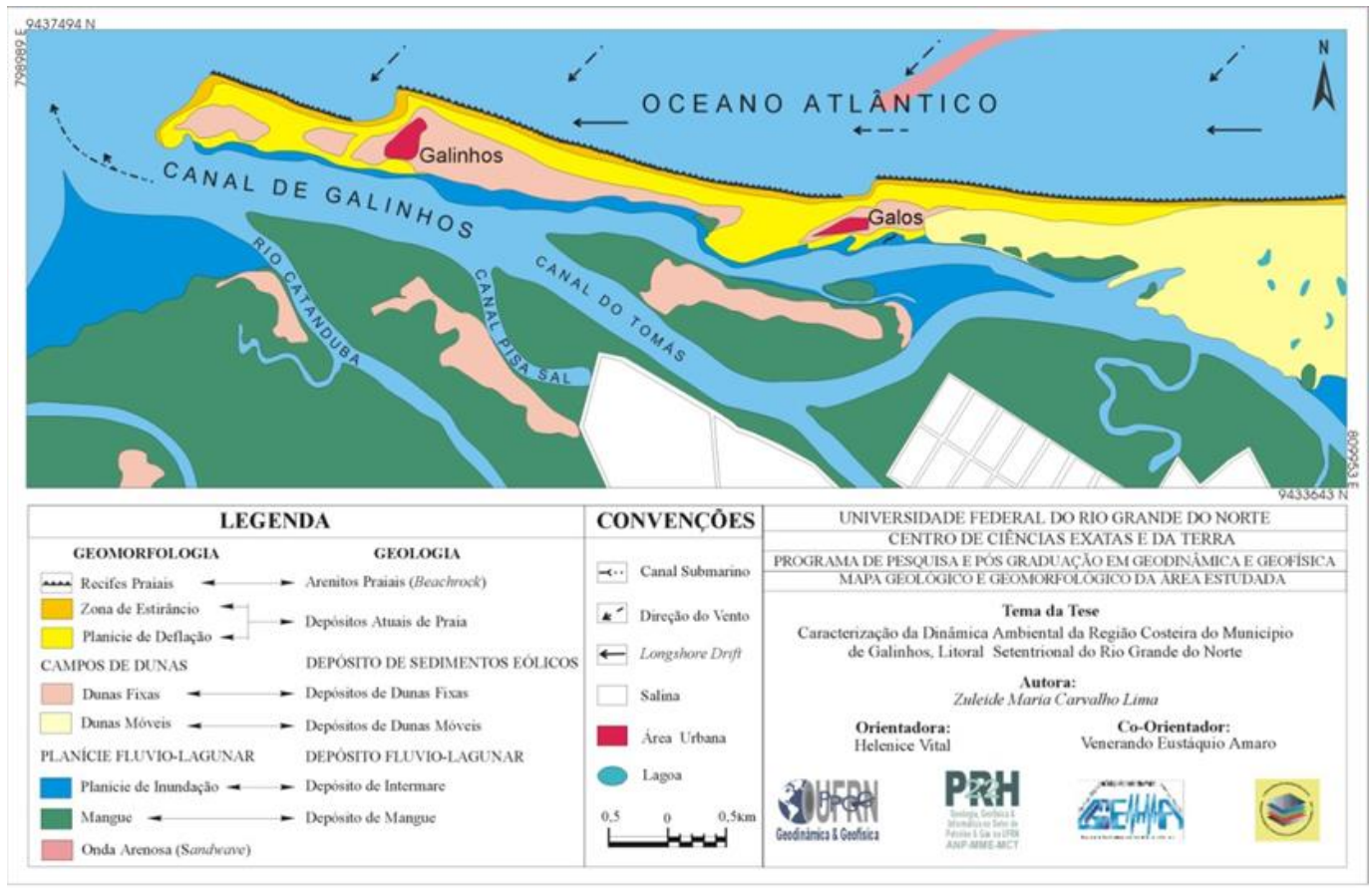


Figura 02 - Mapa Geológico e Geomorfológico da Área em Estudo. Fonte: Lima, 2004.

\section{3 - Metodologia}

Esta pesquisa foi realizada entre os meses de junho a dezembro de 2012, perfazendo então sete (07) meses de monitoramento, e foram sempre em dias de maré de sizígia de lua cheia, em cada referido mês, onde foram feitos perfis de praia (P01, P02 e P03) e levantamento de dados hidrodinâmicos (H01 e H02). Nos perfis de praia, com a utilização de um GPS Geodéssico, definimos as cotas absolutas de cada perfil. Nestes, foram realizados perfis de praia mensal, utilizando como equipamento, o nível, além da mira, balisas e piquetes. Já a coleta de dados hidrodinâmicos englobou a medição da altura das ondas (metodologia adotada por Muehe, 1994 e Chaves, 2005), com régua graduada na linha de praia; Período das ondas, onde utilizamos um cronômetro e um ponto fixo na zona de arrebentação, onde foram contadas 11 ondas, que permitiram uma média de 10 períodos, por um tempo observado, e esta metodologia foi repetida sempre 10 vezes por dia, nos dois pontos de hidrodinâmica (H01 e H02), em todos os meses analisados; A medição da velocidade e direção das correntes litorâneas também foram realizadas no mesmo período das medições acima. Para a obtenção dos dados sobre a velocidade da corrente litorânea, aplicamos a metodologia do cálculo da velocidade, a qual consiste em definir a velocidade através da distância, onde fixamos duas balizas na linha de praia, com uma distância entre elas de 10 metros, medida com uma trena, e com ajuda de um flutuador arremessado na zona de arrebentação; E por fim, definimos o ângulo de incidência das ondas, com ajuda de uma bússola. Todos os dados foram anotados em cadernetas específicas da hidrodinâmica costeira.

Por fim, levaremos em consideração os estádios de equilíbrio da praia, sendo este calculado em função da altura de uma onda na arrebentação (i), do período de uma onda (ii), do calibre dos sedimentos (iii), e da variação destes parâmetros (iv) no tempo, em cada lugar.

O parâmetro $\Omega$ (Dean, 1973), será aqui usado para definir o estádio de equilíbrio da praia. O que pode ser representado pela fórmula: $\Omega=\mathrm{Hb} / \mathrm{Ws}$.T; onde $\mathrm{Hb}$ é a altura da onda na arrebentação, Ws é a velocidade da queda do sedimento médio, e T é o período da onda. Neste, o valor de $\Omega$ define limiares entre os esádios de equilíbrio dinâmico da praia, em que: $\Omega \leq 1$, a praia é Reflectiva, $\Omega 1 \geq \mathrm{a} \leq 6 \mathrm{a}$ praia é intermediária, e $\Omega \geq 6$, a praia é Dissipativa. Salientamos que o valor de Ws foi retirado do trabalho de Chaves (2005), já que a área deste (praia de Macau) é a praia mais próxima da área em estudo.

\section{4 - Resultados Parciais}


Os resultados apresentados, resultam das atividades de campo e laboratório. Os procedimentos de campo foram todos fotografados e este englobou as atividades de coletas e análises dos dados de perfis praiais e da hidrodinâmica costeira.

\section{1 - Perfis de Praia}

Os perfis de praia foram definidos como P01, $\mathrm{P} 02$ e P03, e todos perpendiculares a linha de praia, sendo todos os pontos georreferenciados com cotas absolutas e retirados os seus referidos azimutes com média de $\mathrm{Az} 355^{\circ} \mathrm{NW}$ (Figura 03).

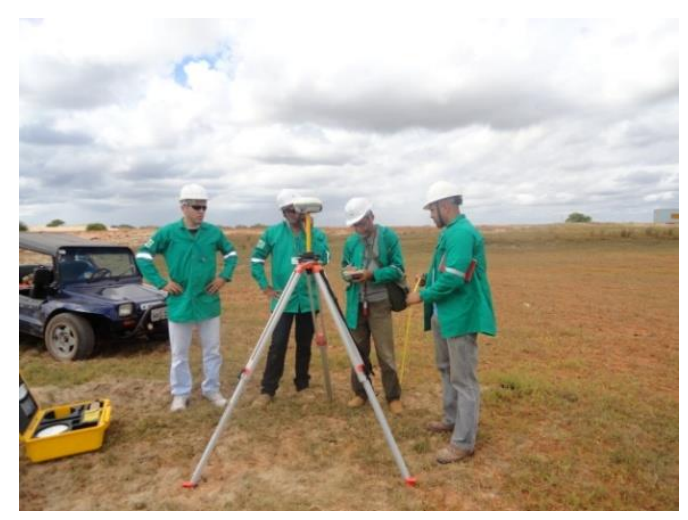

Figura 03 - Determinação das cotas absolutas dos pontos de perfis de praia, georreferenciados com GPS geodéssico. Equipe de Campo. Foto: Marcelo Chaves, 2012.

Os três pontos georreferenciados para os perfis de praias, com base nas coordenadas SAD/69, foram: P01 $\quad(812.821,48 \mathrm{mE} / 9.436 .006,57 \mathrm{mN}), \quad$ P02 $\quad(811.776,73 \mathrm{mE} / 9.436 .043,93 \mathrm{mN}), \quad$ e $\quad$ P03 $(810.684,04 \mathrm{mE} / 9.436 .086,98 \mathrm{mN})$.

Os perfis de praia foram confeccionados conforme a metodologia de nivelamento topográfico. A cota zero está relacionada ao nível de maré de sizígia mais baixa (dado retirado da tábua de marés da marinha do Brasil).

A figura 04 apresenta o Perfil 01, nos sete meses de coleta de dados. Os dados, em todos os perfis estão em metros reais (altitude e comprimento). 


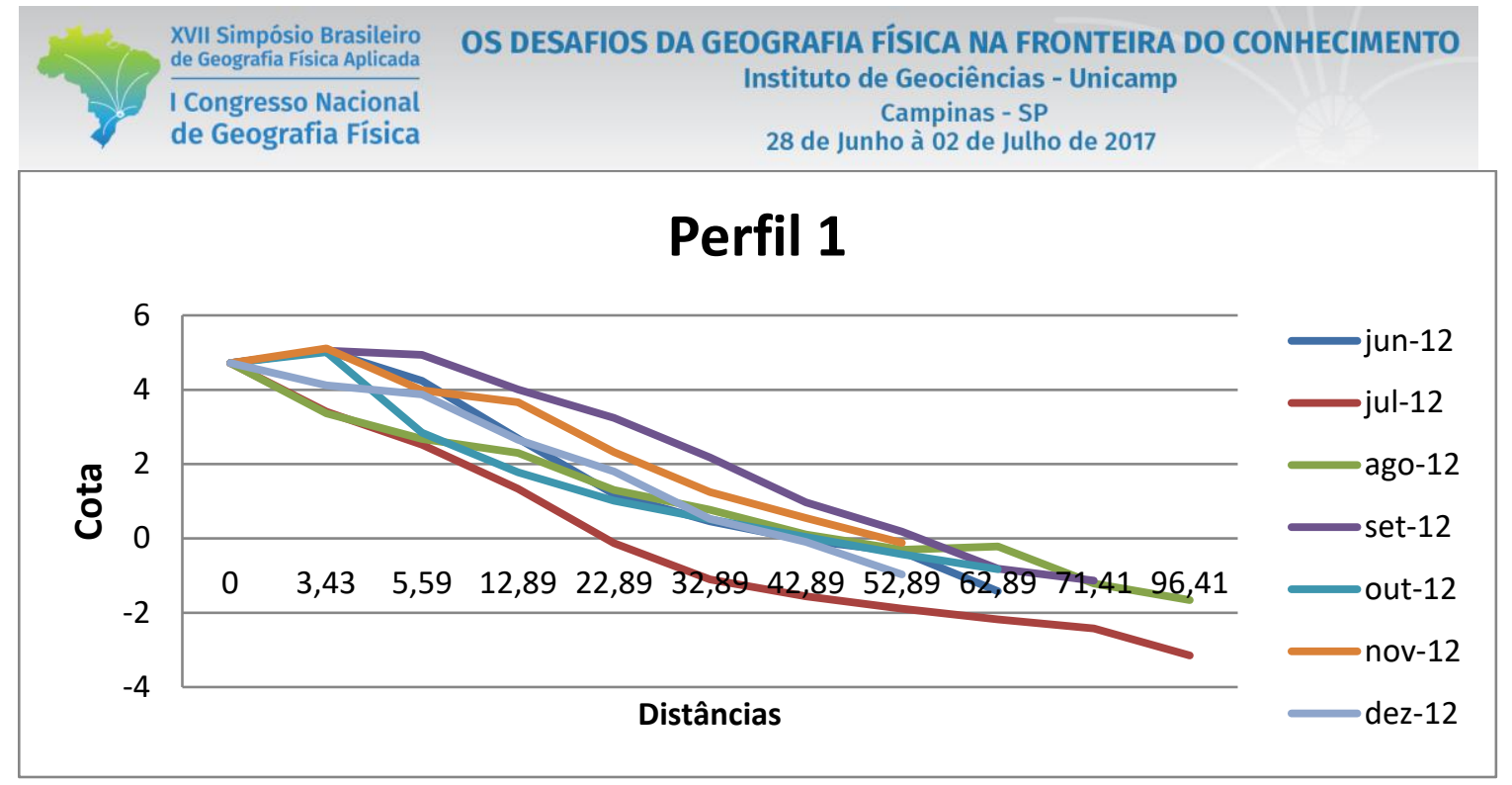

Figura 04 - Perfis de praia do perfil 01, dos meses de junho a dezembro de 2012.

Com os dados do nivelamento topográfico dos perfis, foram confeccionados os perfis de praias propriamente ditos. Já a figura 05 apresenta o Perfil 02, nos sete meses de coleta de dados.

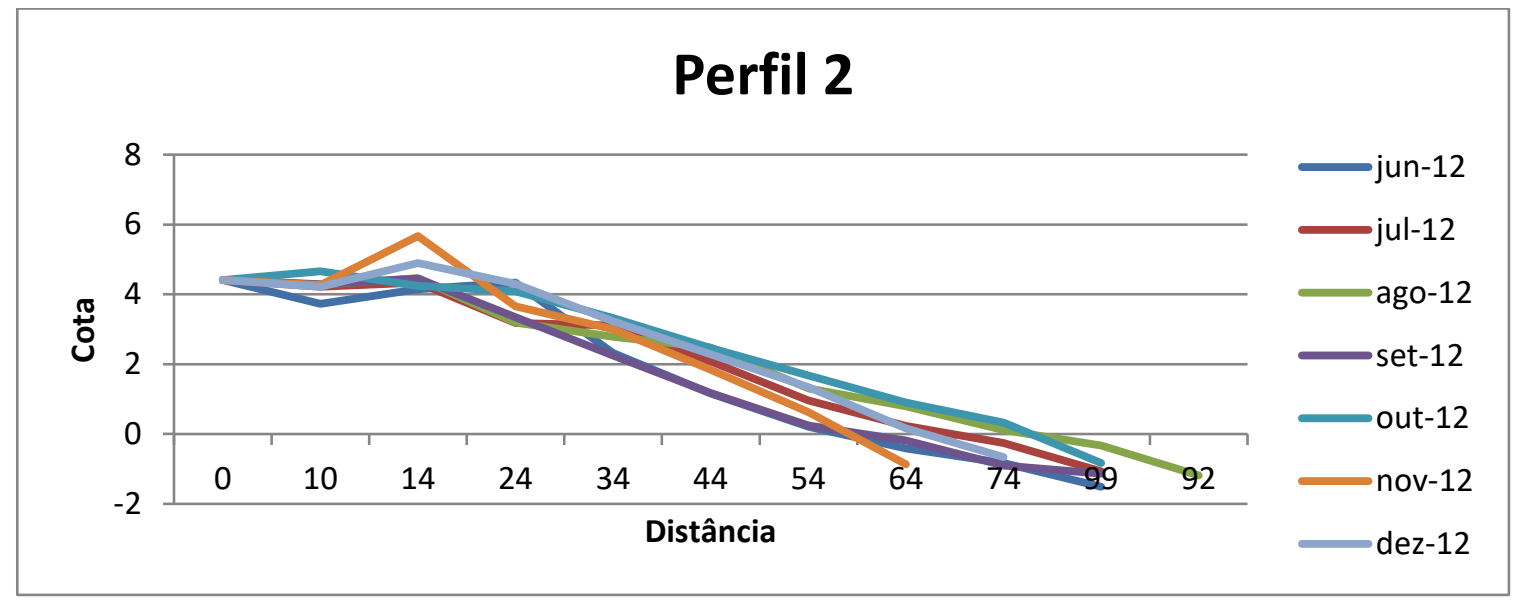

Figura 05 - Perfis de praia do perfil 02, dos meses de junho a dezembro de 2012.

Na figura 06 apresentamos o Perfil 03, nos sete meses de coleta de dados.

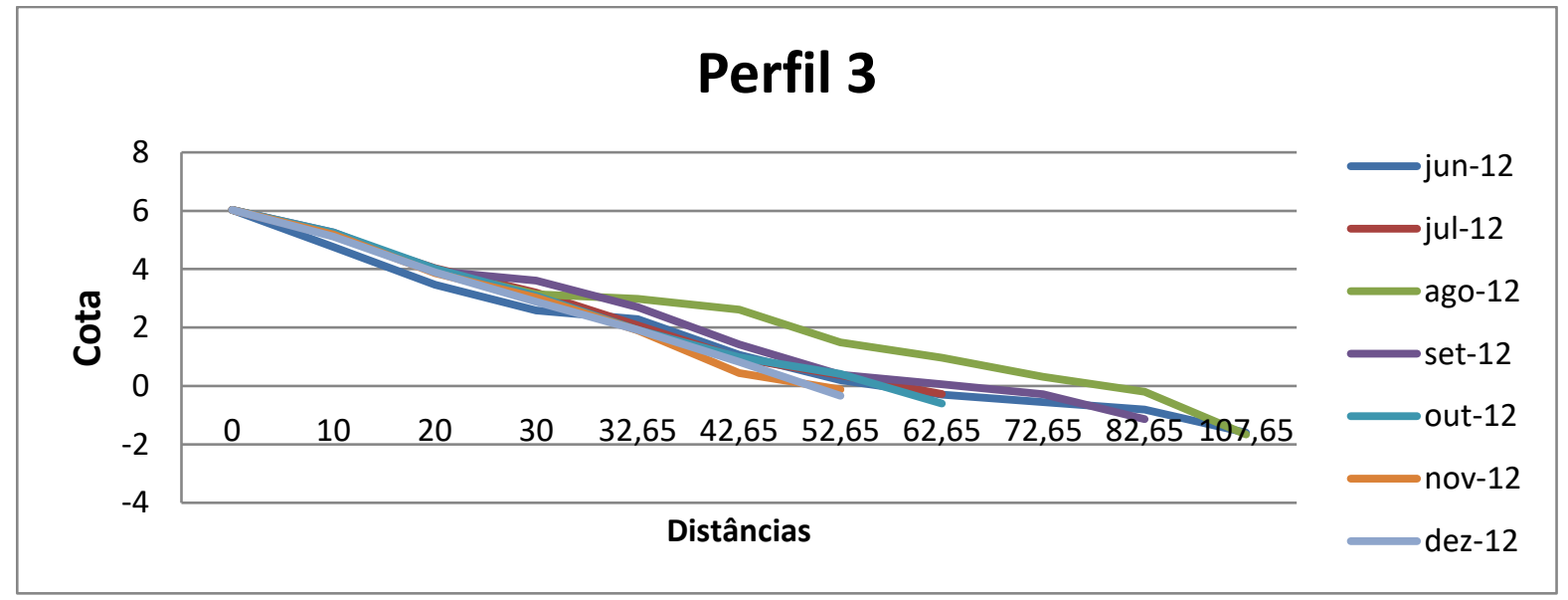

Figura 06 - Perfis de praia do perfil 03, dos meses de junho a dezembro de 2012. 


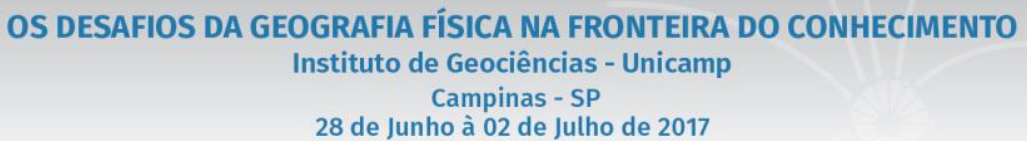

Analisando os três perfis, percebemos que no mês de agosto ocorreu sempre uma formação acentuada de escarpa de berma, com alturas superiores a 1 metro e uma declividade reta de até $90^{\circ}$. Sendo pois, esta feição comum em formar-se neste período do ano, devido as fortes correntes litorâneas e ventos acima da média. No mês de setembro, ocorreu o arrasamento das escarpas de bermas, formadas no mês anterior. Deve-se aqui afirmar que sempre nesses períodos de agosto a setembro, observações devem ser feitas, principalmente pela grande movimentação de areia neste período, na linha de costa. E nos meses de outubro, novembro e dezembro estes apresentaram um comportamento tanto de declividade, arrasamento da berma e sua morfologia, típicas do período de verão.

A metodologia de campo para os perfis 01,02 e 03, nos meses de junho a dezembro, está representada na figura 07.

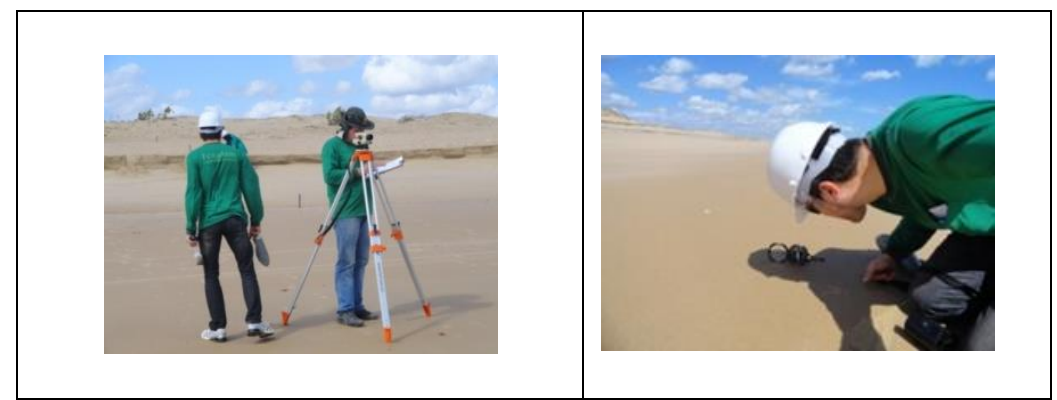

Figura 07 - Metodologias de campo (nivelamento topográfico, a esquerda; e Coleta da declividade do estirâncio, a direita). Fotos: Marcelo Chaves, 2012.

\section{2 - Hidrodinâmica Costeira}

No estudo da hidrodinâmica costeira, levamos em consideração a altura das ondas e o período das ondas (Figura 08).

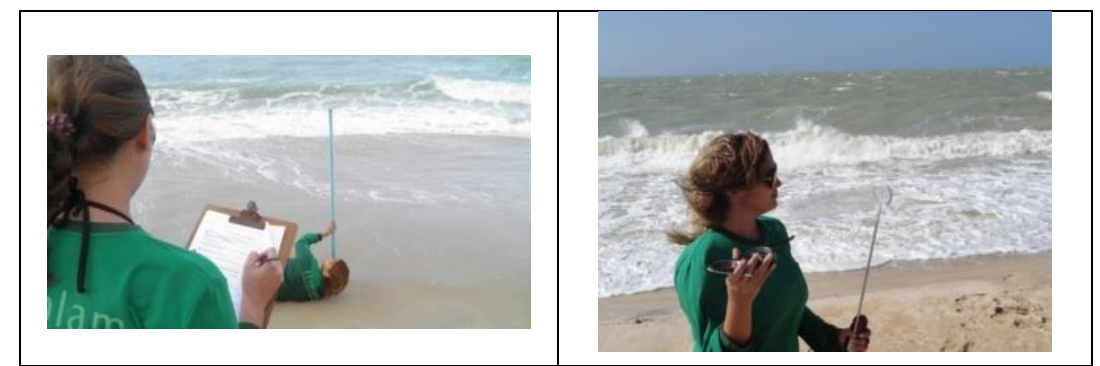

Figura 08 - Metodologia de campo de coleta de dados hidrodinâmicos (altura de ondas, a esquerda; período de ondas, a direita). Fotos: Marcelo Chaves, 2012.

Os dados referentes a alturas e períodos de ondas foram coletados segundo a metodologia científica. E estes foram coletados pela média de doze (12) valores retiradas nos pontos $\mathrm{H} 01$ e H02, sendo estas representadas por uma altura média e um período médio de ondas (Tabelas 01 e 02).

Tabela 01 - Altura média de uma onda $(\mathrm{em} \mathrm{cm})$, no período estudado. 


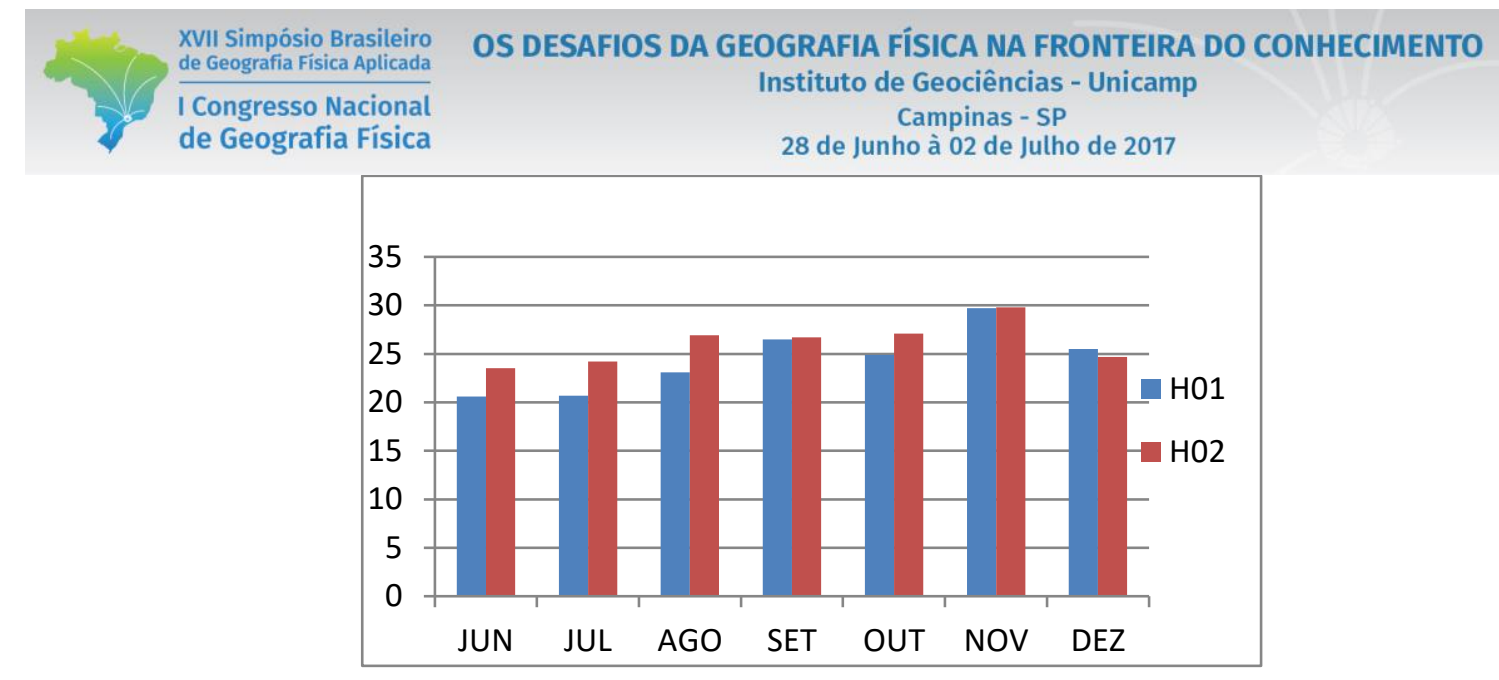

Tabela 02 - Período médio de uma onda, no período estudado.

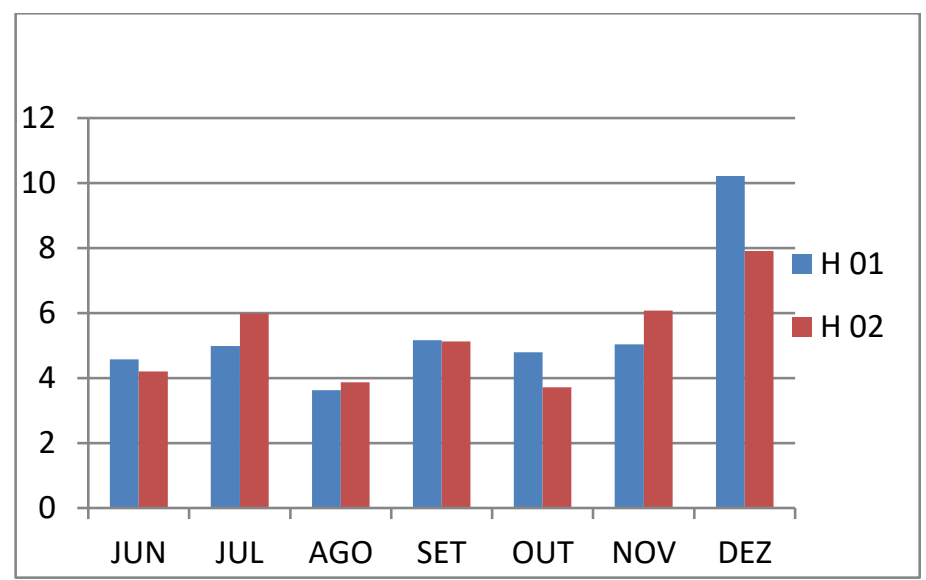

Tanto os valores de alturas como de períodos de uma onda, estão compatíveis com as normais daquela região, conforme dados de outros monitoramentos citados nas referências bibliográficas. Em análise, as maiores alturas de ondas foram registradas no mês de novembro $(29,8 \mathrm{~cm})$ e as menores alturas em junho $(20,6 \mathrm{~cm})$. Já os maiores períodos de ondas, foram registrados no mês de dezembro (10,22 min) e os menores períodos de ondas, em agosto (3,62 $\mathrm{min})$.

A nível de comparação para com os estádios de equilíbrio dinâmico, foram coletados os ângulos de incidência das ondas, que é a diferença em graus, da direção da linha de praia e a direção do trend de ondas, e são observados na tabela 03. Constatamos que o maior ângulo ocorreu em agosto $\left(48^{\circ}\right)$ e o menor em junho e dezembro $\left(5^{\circ}\right)$.

Tabela 03 - Ângulo de incidência das ondas, no período estudado.

\begin{tabular}{|l|c|c|c|c|c|c|c|}
\hline \multicolumn{7}{|c|}{ ÂNGUL DE INCIDÊNCIA DAS ONDAS (em graus) } \\
\hline & JUN & JUL & AGO & SET & OUT & NOV & DEZ \\
\hline H 01 & $5^{\circ}$ & $11^{\circ}$ & $20^{\circ}$ & $15^{\circ}$ & $10^{\circ}$ & $15^{\circ}$ & $15^{\circ}$ \\
\hline H 02 & $15^{\circ}$ & $20^{\circ}$ & $48^{\circ}$ & $20^{\circ}$ & $10^{\circ}$ & $15^{\circ}$ & $05^{\circ}$ \\
\hline
\end{tabular}

\section{5 - Estádio de Equilíbrio Dinâmico da Praia}


OS DESAFIOS DA GEOGRAFIA FÍSICA NA FRONTEIRA DO CONHECIMENTO Instituto de Geociências - Unicamp Campinas - SP

28 de Junho à 02 de Julho de 2017

Para as observações dinâmicas da praia, levamos em consideração os estádios de equilíbrio da praia, sendo este calculado em função da altura de uma onda na arrebentação (i), do período de uma onda (ii), do calibre dos sedimentos (iii), e da variação destes parâmetros (iv) no tempo, em cada lugar. Por definição, o parâmetro de Dean $(\Omega)$ (Dean, 1973), será aqui usado para definir o estádio de equilíbrio da praia. O que pode ser representado pela fórmula: $\Omega=\mathrm{Hb} / \mathrm{Ws} . \mathrm{T}$; onde $\mathrm{Hb}$ é a altura da onda na arrebentação, Ws é a velocidade da queda do sedimento médio, que consideraremos o valor de $28,0 \mathrm{~m} / \mathrm{s}$, para a praia de Macau, e T é o período da onda. Neste, o valor de $\Omega$ define limiares entre os estádios de equilíbrio dinâmico da praia, em que: $\Omega \leq 1$, a praia é Reflectiva, $\Omega 1 \geq$ a $\leq 6$ a praia é intermediária, e $\Omega \geq 6$, a praia é Dissipativa.

Com base nos dados de altura, período e a velocidade de queda dos sedimentos, temos os valores em $\Omega$ em todos os pontos estudados, como sendo de uma praia reflectiva (Tabela 04).

Tabela 04 - Estádio de equilíbrio dinâmico da área em estudo.

\begin{tabular}{|l|c|c|c|c|c|c|c|}
\hline \multicolumn{1}{|c|}{ JUN } & JUL & AGO & SET & OUT & NOV & DEZ \\
\hline H 01 & 0,16 & 0,14 & 0,22 & 0,18 & 0,18 & 0,21 & 0,08 \\
\hline H 02 & 0,19 & 0,14 & 0,24 & 0,18 & 0,26 & 0,17 & 0,11 \\
\hline
\end{tabular}

\section{6 - Considerações Finais}

Para uma análise mais clara sobre o ambiente praial, optamos por analisar cada perfil de praia ao longo do período estudado.

Tanto os valores de alturas como de períodos de uma onda, estão compatíveis como normais daquela região, conforme dados de outros monitoramentos citados nas referências bibliográficas no projeto inicial. Não apresentaram nenhuma anomalia significativa. Sendo a altura média de uma onda, variando de $20,7 \mathrm{~cm}$ a $29,7 \mathrm{~cm}$. E o período médio de uma onda, variando 4,98min a 10,22min, sendo o mês de outubro o mês que apresentou os maiores valores. Já a velocidade da corrente litorânea variou de $0,21 \mathrm{~m} / \mathrm{s}$ a $0,76 \mathrm{~m} / \mathrm{s}$. E a direção da corrente litorânea manteve-se em média com Az $280^{\circ} \mathrm{NW}$.

No Perfil 01, todos os compartimentos de praia encontram-se muito íngremes, em especial atenção ao estirâncio, que possui uma declividade alta. Sendo este, ficando nos meses posteriores, cada vez mais alta. Porém, a partir de setembro, esta declividade diminui consideravelmente, chegando a $1^{0}$. E a partir de novembro até dezembro, esta declividade volta a subir a $7^{0}$.

Já no Perfil 02, percebemos a presença de uma escarpa de berma proeminente, sendo característica de áreas com boa proteção a ação erosiva das ondas. Este apresentou uma zona de pós-praia bastante elevada e com vegetação. Em setembro, a declividade do estirâncio foi de $3^{0}$. Já em outubro, este apresentou uma zona de pós-praia e estirâncio completamente arrasadas, porém, com variações de volume de areia nestes dois compartimentos de relevos, sendo já visualizadas os arenitos recifais. 
Notamos também que em outubro, a declividade do estirâncio foi de $7^{\circ}$, sendo esse processo de erosão acentuada, registrado pela presença dos arenitos recifais, mesmo ainda havendo formação de uma berma proeminente. Este ainda é um perfil que preocupa quanto a erosão costeira, principalmente por haver uma pós-praia arrasada, sem formação de duna, e pouca vegetação. . Nos meses finais, de novembro e dezembro, este apresentou uma zona de estirâncio em processo de erosão, com declividade de $7^{\circ}$, aspecto esse que já vem sendo registrado nos meses anteriores. Porém, nota-se que ainda encontra-se formada a escarpa de berma, mesmo com o perfil em declive até a antepraia.

No Perfil 03, entre os meses de junho e julho, é ausente escarpa de berma, como também, variações altimétricas no compartimento de relevo da pós-praia até a antepraia, o que denota uma certa fragilidade quanto a ação erosiva das ondas. Observamos que no mês de agosto, este é o perfil mais erodido em todos os compartimentos de relevos, sendo este o que preocupa quanto a erosão costeira, principalmente por haver uma pós-praia arrasada, sem formação de duna e/ou vegetação. Já em setembro, observamos que este perfil foi quase que completamente reconstituído, mas mesmo assim, é aqui o perfil que apresentou a maior declividade do estirâncio. Em outubro, a declividade do estirâncio foi de $5^{\circ}$. Em novembro, observamos que este continua em processo de erosão, com as maiores declividades do estirâncio. E por fim, em dezembro, observamos que é nítido o declive em todos os compartimentos de relevos, sendo este mês $4^{\circ}$. Este ainda é um perfil que preocupa quanto a erosão costeira, principalmente por não haver formação de escarpas de bermas. Sendo pois, necessário um monitoramento cíclico maior que um período de um ano, para análise do comportamento da evolução ou não deste compartimento de relevo. Com base nos dados hidrodinâmicos de altura, período e a velocidade de queda dos sedimentos, temos os valores em $\Omega$ em todos os pontos estudados, como sendo de uma praia reflectiva

\section{REFERÊNCIAS}

ALMEIDA, F. F. M.; HASSUI, Y.; BRITO NEVES, B. B. \& FUCK, R. A. 1977. Províncias estruturais brasileiras. In: SBG, Simpósio de Geologia do Nordeste, 2, Campina Grande, Anais..., 242-258.

BITTENCOURT, A. C. S. P.; FARIAS, F. F. and ZANINI Jr., A. 1987. Reflexo das variações morfodinâmicas praiais nas características texturais dos sedimentos de praia da Armação. Salvador, BA. Revista Brasileira e Geociências, 17 (3), 276-282.

CESTARO, L. A. 1994. Os elementos do clima de Galinhos, RN como recursos naturais à disposição do homem. Caderno Norte-Rio-Grandense de Temas Geográficos, Natal, v.8, n.1, p. 13-28.

CHAVES, M. dos S. 2005. Dinâmica Costeira dos Campos Petrolíferos Macau/Serra, Litoral Setentrional do Estado do Rio Grande do Norte. Tese de Doutorado, N 10/PPGG, 117p. UFRN. Natal/RN.

DEAN, R. G. \& DALRYMPLE, R. A. 2002. Coastal processes with Engineering Applications. Cambridge University Press. 475p. e p.221.

DEAN, R. G. 1973. Heuristic Models of Sand Transport in the Surf Zone. In: Proceedingns of the Conference on Engineering Dynamics in the Surf Zone. Sidney, p.208-214. 
ECOPLAM - Empresa de Consultoria e Planejamento Ambiental. 1990. Diagnóstico das condições ambientais do sistema estuarino-lagunar de Galinhos/RN, Natal (RN).

EMBRAPA. 1999. Sistema Brasileiro de Classificação dos Solos. Brasília:EMBRAPA, 412p.

FIERN - Federação das Indústrias do Estado do Rio Grande do Norte. 1998. Plano Diretor de Implantação do Pólo Gás-Sal: sumário executivo. Natal: FIERN 1998. 68p.

KOMAR, P. D. 1998. Beach processes and sedimentation. Prentice Hall.. 2 edição. 544p.

LIMA, Z. M. C., ALVES, A. L., AMARO, V. E., VITAL, H. 2001. Coastline Evolution of The Galinhos Spit (Ne Brazil) Using Air Photography And Landsat TM Images. Revista Pesquisas em Geociências. (Ed.) UFRSRS. 28, 497-507.

LIMA, Z. M. C. 2004. Caracterização da Dinâmica Ambiental da Região Costeira do Município de Galinhos, Litoral Setentrional do Rio Grande do Norte. Tese (Doutorado em Geodinâmica), Universidade Federal do Rio Grande do Norte, Natal (Tese PPGG,5). 144p.

MUEHE, D. 1994. Geomorfologia Costeira. In: Guerra, A. J. T. \& Cunha, S.B. (eds). Geomorfologia: uma atualização de bases e conceitos. Rio de Janeiro, Bertrand Brasil. P. 253-308.

NIMER, E. 1989. Climatologia do Brasil. IBGE. Rio de Janeiro, $2^{a}$ edição. 422p.

OLIVEIRA, J. B. de; JACOMINE, P. K. T.; CAMARGO, M. N. 1992. Classes Gerais de solos do Brasil: Guia auxiliar para o seu reconhecimento. 2. ed. Jaboticabal, FUNEP. 201p.

SAAGA, A. M. S. 1992. The use of the textural parameters of sand in studying the characteristics and depotional processes of coastal sediments south of Jeddah. Saudi Arabia. Marine Geology, 104:179-186.

SHORT, A. D. 1999. Wave-dominated beaches In: Short, A. D. (ed.). Handbook of beach and shoreface morphodynamics. John Wiley \& Sons Ltd. P.173-203.

SUDENE, 1971. Levantamento Exploratório de Solos do Estado do Rio Grande do Norte: Série, Pedologia, 9, Recife/PE. 531 + Anexo: Mapa Exploratório - Reconhecimento de Solo do Estado do Rio Grande do Norte. 1968, escala 1:500.000. 